\title{
Morphophysiological and phytochemical responses of fenugreek to plant growth promoting rhizobacteria (PGPR) under different soil water levels
}

\author{
Ali Sharghi', Hassanali Naghdi Badi ${ }^{2 *}$, Sahebali Bolandnazar ${ }^{3}$, \\ Ali Mehrafarin ${ }^{2}$, Mohammad Reza Sarikhani ${ }^{4}$
}

${ }^{1}$ Department of Horticulture, Science and Research branch, Islamic Azad University, Tehran, Iran

${ }^{2}$ Medicinal Plants Research Center, Institute of Medicinal Plants, ACECR, Karaj, Iran

${ }^{3}$ Department of Horticulture Science, University of Tabriz, Tabriz, Iran

${ }^{4}$ Department of Soil Science, University of Tabriz, Tabriz, Iran

\begin{abstract}
Fenugreek (Trigonella foenum-graecum L.) is a valuable medicinal plant, which is widely distributed throughout the world. It has been known that plant growth promoting rhizobacteria (PGPR) have positive effects on the quality and quantity of medicinal plants under different soil water levels. For this reason, a factorial experiment was conducted on the basis of a randomized complete block design (RCBD) to evaluate PGPR effects on the morphophysiological and phytochemical traits of fenugreek under different soil water levels. This study was conducted in two separate experiments: after the six-leaf stage and after the flowering stage. In the experiments, the treatments were plant growth promoting rhizobacteria (PGPR) including the control, Sinorhizobium meliloti, Pseudomonas fluorescens, a combination of S. meliloti and P. fluorescens, and different soil water levels (i.e. $100,80,60$ and 40\% of field capacity (FC) in three replications. The results showed that the highest seed weight per plant was obtained by inoculation with the $S$. meliloti and P. fluorescens combination at 100\% FC after the two developmental stages. The maximum concentrations of nicotinic acid and trigonelline were observed for the combination of $S$. meliloti and P. fluorescens at the soil water content of $40 \%$ FC after the six-leaf stage and for $S$. meliloti at the soil water content of $40 \% \mathrm{FC}$ after the flowering stage. The correlation and stepwise regression analyses showed positive effects of PGPR application on the morphophysiological and phytochemical traits of fenugreek plants under different soil water levels.
\end{abstract}

Keywords: nicotinic acid, Pseudomonas fluorescens, Sinorhizobium meliloti, soil water content, Trigonella foenum-graecum L., trigonelline

Abbreviations:

PGPR - plant growth promoting rhizobacteria, FC - field capacity, WUE - plant water-use efficiency, SPAD value - a relative chlorophyll index which is measured by SPAD meter

\section{INTRODUCTION}

Insufficient water induces a stress in plants called water deficit stress (Dodd and Ryan, 2016). Water stress has major effects on plant growth and development, limiting crop production worldwide. Water stress negatively affects plant growth and reproduction, and disrupts whole-plant functions (Bray, 2004; Hummel et al., 2010). Water stress

\footnotetext{
*Corresponding author. 
causes cellular changes such as solute concentration and cell volume alterations, disruption of water potential gradients, changes in membrane shape and impairment of its integrity, loss in turgor pressure, and protein denaturation (Bray, 1997; Bartels and Sunkar, 2005). Water stress is a major threat to crop production, and tolerance to drought conditions is the main target for crop improvement (Salekdeh et al., 2009). However, there have been reports on increasing secondary metabolites under water stress. It has been reported that the biosynthesis of these metabolites is not only under the influence of plant genetics but is also affected by changes in environmental factors (Aliabadi-Farahani et al., 2009). Water stress has limited the production of many crops worldwide and negatively affects plant growth and reproduction. Recently published reports have indicated that plant growth promoting rhizobacteria (PGPR) ameliorate plant tolerance to abiotic stresses through a variety of mechanisms (Jaleel et al., 2007; Srivastava et al., 2008; Sandhya et al., 2010). Previous studies indicated that a specific pathway for the synthesis of secondary metabolites in medicinal plants was induced by micro-organisms such as PGPR (Bouchereau et al., 1996). According to the report by Turtola et al. (2003), due to drought stress, during photosynthesis, carbon fixation is used to produce secondary metabolites. On the other hand, one of the activities of PGPR is the production of phytohormones. Phytohormones, especially auxins, control several stages of plant growth and development such as cell elongation, cell division and tissue differentiation (Vessey, 2003). A plant under a long-term treatment with an auxin (IAA) has highly developed roots, which in turn allows the plant to better take up nutrients, ultimately aiding the overall growth of the plant (Aeron et al., 2011). This action, especially at low water levels, helps to increase the production of secondary metabolites. PGPR are rhizosphere bacteria which develop symbiotic relationships with large varieties of plants and are used as biofertilizer (Shaukat et al., 2006). It has been reported that PGPR have positive effects and induce plant resistance to environmental stresses and diseases caused by pathogens (Jing et al., 2007; Dimkpa et al., 2009; Yang et al., 2009). A wide variety of mechanisms that can improve plant growth have been suggested to be induced by PGPR. The mechanisms involved are as follows: nitrogen fixation (van Loon, 2007), synthesis of 1-Aminocyclopropane-1-carboxylate deaminase (ACC) (Govindasamy et al., 2008), synthesis of volatile organic compounds (Ryu et al., 2003), phytohormone synthesis (Vessey, 2003), siderophore production (El-Tarabily and Sivasithamparam, 2006), phosphate solubilization (Ryu et al., 2003), and synthesis of secondary metabolites (Bouchereau et al., 1996).

Fenugreek (Trigonella foenum-graecum L.) is a member of the Fabaceae family, and is grown as a spice and vegetable crop. Fenugreek has indeterminate growth, which allows greater flexibility in the timing of harvest. Fenugreek has been used in traditional therapy as a remedy for diabetes (Miraldi et al., 2001; Basch et al., 2003; Fernandez-Aparicio et al., 2008). Also, its effects as an anti-diabetic and anti-atherosclerotic have previously been well documented (Ajabnoor and Tilmisany, 1988; Sharma and Raghuram, 1990). Fenugreek leaves are a rich source of iron, calcium, $\beta$-carotene and other vitamins, while its seeds contain tannic acid, diosgenin, trigocoumarin, alkaloids, trigonelline, trigomethyl coumarin, gitogenin, and vitamin A (Warke et al., 2011), which indicates its nutritional and medicinal value (Danesh Talab et al., 2014).

Although fenugreek is a valuable medicinal plant, the effect of different soil water levels after the six-leaf stage and the flowering stage, and the effect of PGPR on the qualitative and quantitative yield of fenugreek have not been well documented. The aim of the present study was a comparative investigation of PGPR effects on fenugreek (Trigonella foenumgraecum L.) under different soil water levels after the six-leaf stage and the flowering stage. Therefore, the concentrations of the most important medicinal metabolites of this plant (trigonelline and nicotinic acid) and morphophysiological traits were measured to understand these effects.

\section{MATERIAL AND METHODS}

The seeds of fenugreek with a proper germination percentage were provided by the Seed Technology Laboratory of the Medicinal Plants Institute, Academic Center for Education, Culture and Research (ACECR). The present investigation was conducted in a research greenhouse of the Agriculture Faculty of the University of Tabriz during 2015-2016 in two separate experiments after the six-leaf stage (14 days after planting), and after the flowering stage (40 days after planting) until the harvest of plants.

This experiment was conducted on the basis of a factorial experiment in a randomized complete block design (RCBD) with three replications. The first factor was application of PGPR in 4 variants 
including Sinorhizobium meliloti as nitrogen fixing bacteria, Pseudomonas fluorescens as phosphatesolubilizing bacteria, combination of $S$. meliloti and $P$. fluorescens, and the control without any bacteria or fertilizer. The second factor was soil water content based on field capacity $(\mathrm{FC}=24.42 \%$ $\mathrm{w} / \mathrm{w}$ equivalent to the $-10 \mathrm{kPa}$ moisture content). The FC of the soil was determined using a pressure plate under a pressure of $0.1 \mathrm{~atm}$, and soil moisture content was calculated, and then different levels of FC were applied in the experiment $(100,80,60$ and $40 \%$ FC).

The main characteristics of the soil were: $\mathrm{pH}$ 7.36; $3.36 \mathrm{dS} \mathrm{m}^{-1} \mathrm{EC} ; 1.79 \%$ organic carbon; $15 \%$ clay; $16 \%$ silt; $73 \%$ sand; $87.4 \mathrm{mg} \mathrm{kg}^{-1}$ available $\mathrm{P}$ (Olsen method); $1250 \mathrm{mg} \mathrm{kg}^{-1} \mathrm{~K} ; 31.85 \% \mathrm{CaCO}_{3}$; $0.12 \%$ total N. Seeds of fenugreek were sown into plastic pots with a surface diameter of $24 \mathrm{~cm}$, each filled with $5 \mathrm{~kg}$ soil. After the establishment of seedlings, 5 plants remained in each pot. Soil water content was maintained in the amounts specified for the treatments by weighing the pot-soil-plant system daily, always in late afternoon, in order to allow the soil to equilibrate with the desired water content during the night. The plants were kept in a greenhouse under a $16 \mathrm{~h}$ photoperiod, $24 \pm 4 / 18 \pm 3{ }^{\circ} \mathrm{C}$ day/night temperatures, and 40$60 \%$ relative humidity. At the end of the experiment, after the ripening of seeds, plants were cut off near the soil level. The plant material was dried in the laboratory at room temperature $\left(26 \pm 2^{\circ} \mathrm{C}\right)$, away from sunlight to prevent changes in the nature of the plants' constituents, and then the seeds were separated. Plant water-use efficiency (WUE) was calculated as the amount of water used per unit of plant material expressed by the ratio of total net dry matter (DM) production to water consumption (Karimi et al., 2014).

For the measurement of leaf SPAD value, nine leaves from each pot were selected and the mean of the leaf SPAD value was measured with a SPAD-502 meter (Konica-Minolta, Japan). The concentrations of potassium and phosphorus were determined by nitric perchloric and nitric acid digestion methods (Havlin and Soltanpour, 1980). Phosphorus was measured by the vanadate-molybdate method using a spectrophotometer (Motic, CL-45240-00, China), and $\mathrm{K}$ was determined using a flame photometer (Model 405G, Iran). Nitrogen was measured according to the Kjeldahl method that involved changing the form of organic nitrogen to the ammonium $\left(\mathrm{NH}_{4}^{+}\right)$form with concentrated sulfuric acid and then measuring the amount of ammonium production (Baker and Thompson, 1992).

\section{Microbial inoculation}

Sinorhizobium meliloti and Pseudomonas fluorescens were used in the assays. The bacterial inocula were prepared using the method presented by Bharti et al. (2014) with slight modifications. Rhizobacterial strains were grown in a nutrient broth (NB) with $5 \%(\mathrm{w} / \mathrm{v}) \mathrm{NaCl}$ (sodium chloride maintains the osmotic equilibrium of the medium) up to a late exponential growth phase to prepare bacterial inocula. The broth in each flask was inoculated with the isolated rhizobacterial strains and incubated at $28^{\circ} \mathrm{C}$ for $24 \mathrm{~h}$ in an orbital shaking incubator at $100 \mathrm{rpm}$. Optical density was measured to achieve a uniform population of bacteria $\left[10^{8}\right.$ colony forming units (CFU) $\mathrm{ml}^{-1}$ ] in the broth prior to inoculation. The required inocula of each culture were centrifuged at $8000 \times \mathrm{g}$ for $10 \mathrm{~min}$. The pellets obtained were washed with sterile distilled water and then dissolved in a $0.85 \%$ saline solution. The bacterial suspension was adjusted to $\mathrm{Abs}_{600 \mathrm{~nm}}$ $=1.0$. The suckers were dipped in their respective treatments for half an hour before planting and the residual bacterial culture suspensions $(5 \mathrm{ml}$ per pot) were also poured into their respective treatments after planting. Pots with no rhizobacterial inoculation (control) received sterilized $0.85 \%$ saline solution (no inoculum).

\section{Isolation and extraction of mucilage}

Fenugreek seeds (200 g) were soaked in distilled water $(1.5 \mathrm{~L})$ at room temperature for $1 \mathrm{~h}$ and then boiled while being stirred in a water bath until a slurry was obtained. The solution was cooled and kept in a refrigerator overnight to settle out undissolved materials. The clear solution above the sediment was decanted and centrifuged at $24 \times \mathrm{g}$ for 20 minutes. The supernatant was separated and concentrated in a water bath at $60^{\circ} \mathrm{C}$ to one third of its original volume. The solution was cooled to room temperature and poured into thrice the volume of acetone with continuous stirring. The precipitate was washed repeatedly with acetone and dried at $50-60^{\circ} \mathrm{C}$ under vacuum. The dried material was powdered and kept in a desiccator (Sabale et al., 2009).

\section{Measurement of trigonelline}

To estimate trigonelline in the samples (seed and/or shoot), the Zheng and Ashihara method (Zheng and Ashihara, 2004) was used with a slight modification. The samples were ground with $80 \%$ methanol and magnesium oxide $(\mathrm{MgO})$ in a mortar 
and pestle. After incubation at $60^{\circ} \mathrm{C}$ for $30 \mathrm{~min}$, the homogenates were centrifuged and the supernatant was collected. After the complete evaporation of methanol, the methanol-soluble extracts were dissolved in distilled water. The samples were filtered using a disposable syringe filter unit and the aliquots were used for the determination of trigonelline (TG) by HPLC. The analyses of the samples were carried out using a Knauer K2600A liquid chromatograph (Germany) equipped with a Nucleosil C18 $(150 \mathrm{~mm} \times 4.6 \mathrm{~mm}$ I.D, $5 \mu \mathrm{m})$ column. A mixture of methanol:water $(50: 50 \mathrm{v} / \mathrm{v})$ served as the mobile phase and the $\mathrm{pH}$ of solution was adjusted to 5.0 with $50 \mathrm{mM}$ sodium acetate. Elution was performed in an isocratic mode at a flow rate of $1 \mathrm{~mL} \mathrm{~min}^{-1}$, and detection was at $268 \mathrm{~nm}$ by UV detector from the above mentioned company (Koshiro et al., 2006; Khosravi et al., 2011). One analysis required $20 \mathrm{~min}$. The retention time of this alkaloid was $4.4 \mathrm{~min}$. Before carrying out HPLC analysis, we made a calibration curve $\left(R^{2}=0.99\right)$ by using different concentrations $(0.1,0.2,0.5,0.7$ and $\left.1.0 \mathrm{mg} \mathrm{mL}^{-1}\right)$ of trigonelline in phase media.

\section{Measurement of nicotinic acid}

To estimate nicotinic acid, the Martin method (Martin et al., 1997) was slightly modified and used. 0.5 grams of the fenugreek seed powder was mixed with 0.5 grams of magnesium oxide $(\mathrm{MgO})$, and $30 \mathrm{ml}$ of distilled water was added to it. The resulting mixture was placed in a water bath at $100^{\circ} \mathrm{C}$ for 30 minutes. After cooling, the resulting mixture was filtered using a filter paper (\# 1) and was made up to a volume of $50 \mathrm{ml}$ with distilled water. Finally, absorption at a wavelength of $263 \mathrm{~nm}$ by the samples was measured with a spectrophotometer. Nicotinic acid concentrations were determined using a standard curve. To determine the standard curve, concentrations of $20,40,60,80$ and 100 micrograms per $\mathrm{ml}$ of nicotinic acid powder were prepared in distilled water, and then magnesium oxide $(\mathrm{MgO})$ was added to the concentration equal to each standard, and absorbance at $263 \mathrm{~nm}$ was measured after smoothing.

\section{Data analysis}

All collected data were subjected to two-way analysis of variance (ANOVA) through PROC GLM procedure, using an SAS statistical package (SAS Institute, software version 9.4, Cary, NC, USA). Means were compared with Duncan's multiple range tests to determine whether the means of the dependent variable were significantly different at $p \leq 0.05$.

\section{RESULTS}

According to the results of variance analysis, the interaction effect of plant growth promoting rhizobacteria (PGPR) and different water availability was significant $(p \leq 0.01)$ on the number of leaves per plant, shoot dry weight, legume number per plant, seed number per legume, 1000 seed weight, seed weight per plant, water use efficiency, SPAD value, seed mucilage content, nicotinic acid and trigonelline content in the two experiments (Tabs 1 and 2).

\section{Induction of water availability after the 6-leaf stage ( $1^{\text {st }}$ experiment)}

Considering the results of means comparisons, the highest number of leaves per plant and shoot dry weight were observed following inoculation with S. meliloti at $100 \%$ FC. The maximum legume number per plant, seed number per legume, 1000 seed weight, seed weight per plant, and also SPAD value, nitrogen, phosphorous and potassium content were obtained by inoculation with $S$. meliloti + P. fluorescens at $100 \%$ FC. The greatest water use efficiency and also the highest amounts of nicotinic acid and trigonelline were related to the treatment with $S$. meliloti + P. fluorescens at $40 \%$ FC. The highest amount of seed mucilage was obtained by inoculation with P. fluorescens at 60\% FC (Tab. 3).

\section{Induction of water availability after the flowering stage ( $2^{\text {nd }}$ experiment)}

The results of mean comparisons showed that the highest leaf number per plant, shoot dry weight per plant, legume number per plant, seed number per legume, 1000 seed weight, seed weight per plant, and also the amounts of seed mucilage, nitrogen and potassium were obtained by inoculation with S. meliloti + P. fluorescens at $100 \%$ FC. The maximum water use efficiency was observed in the treatment with $S$. meliloti at $40 \%$ FC. The highest amounts of trigonelline and nicotinic acid were obtained in the treatment with P. fluorescens at $40 \%$ FC (Tab. 3). The greatest phosphorous content was obtained in the treatment with $P$. fluorescens at $100 \% \mathrm{FC}$.

The correlation between the mentioned traits in the $1^{\text {st }}$ experiment (Tab. 4) showed that trigonelline had a significant $(p \leq 0.01)$ and positive correlation with nicotinic acid. Trigonelline and nicotinic acid had significant and negative correlations $(p \leq 0.01)$ with shoot dry weight, legume number per plant, seed weight per plant and SPAD value, while they showed a significant and positive correlation with 

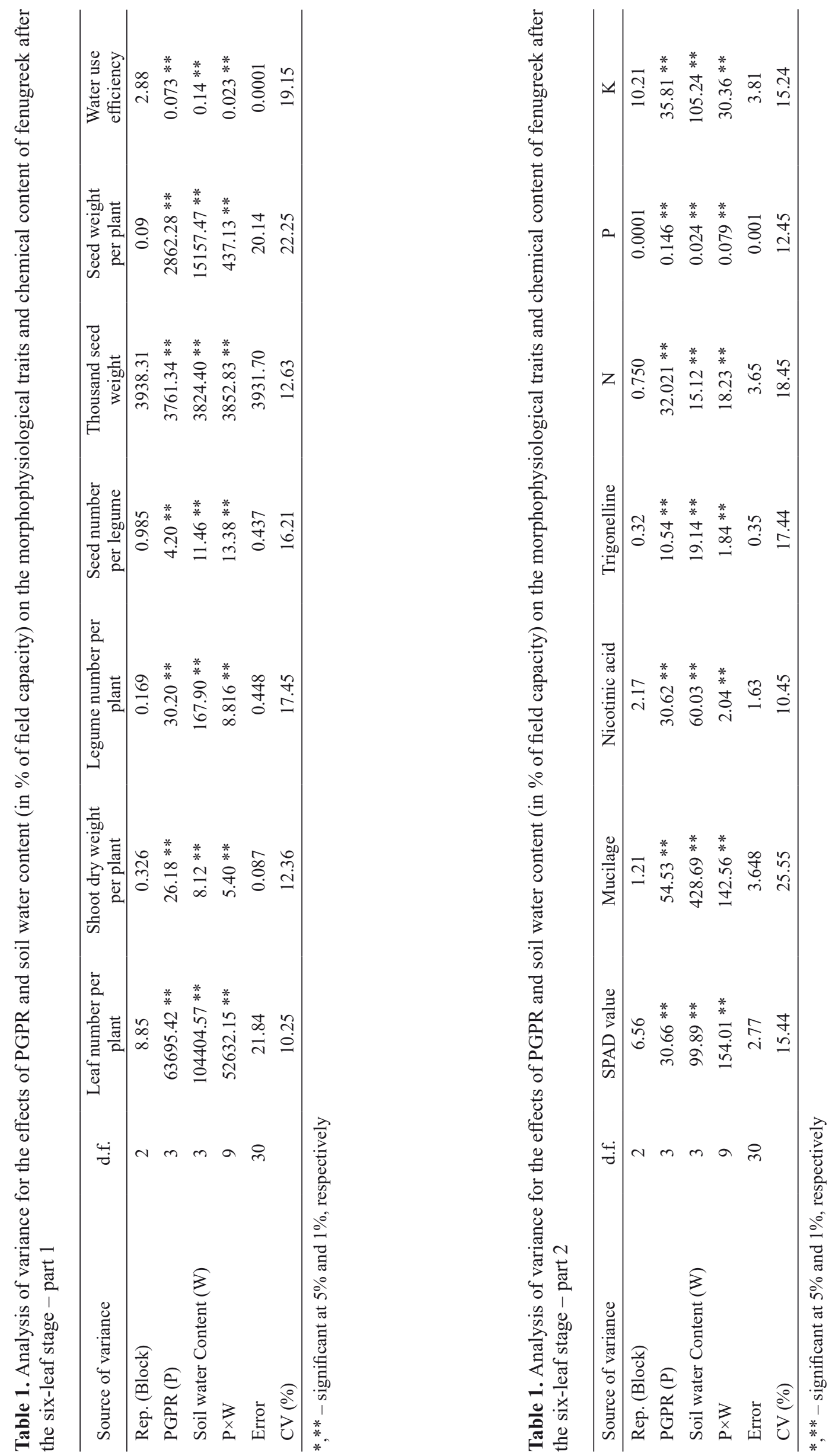

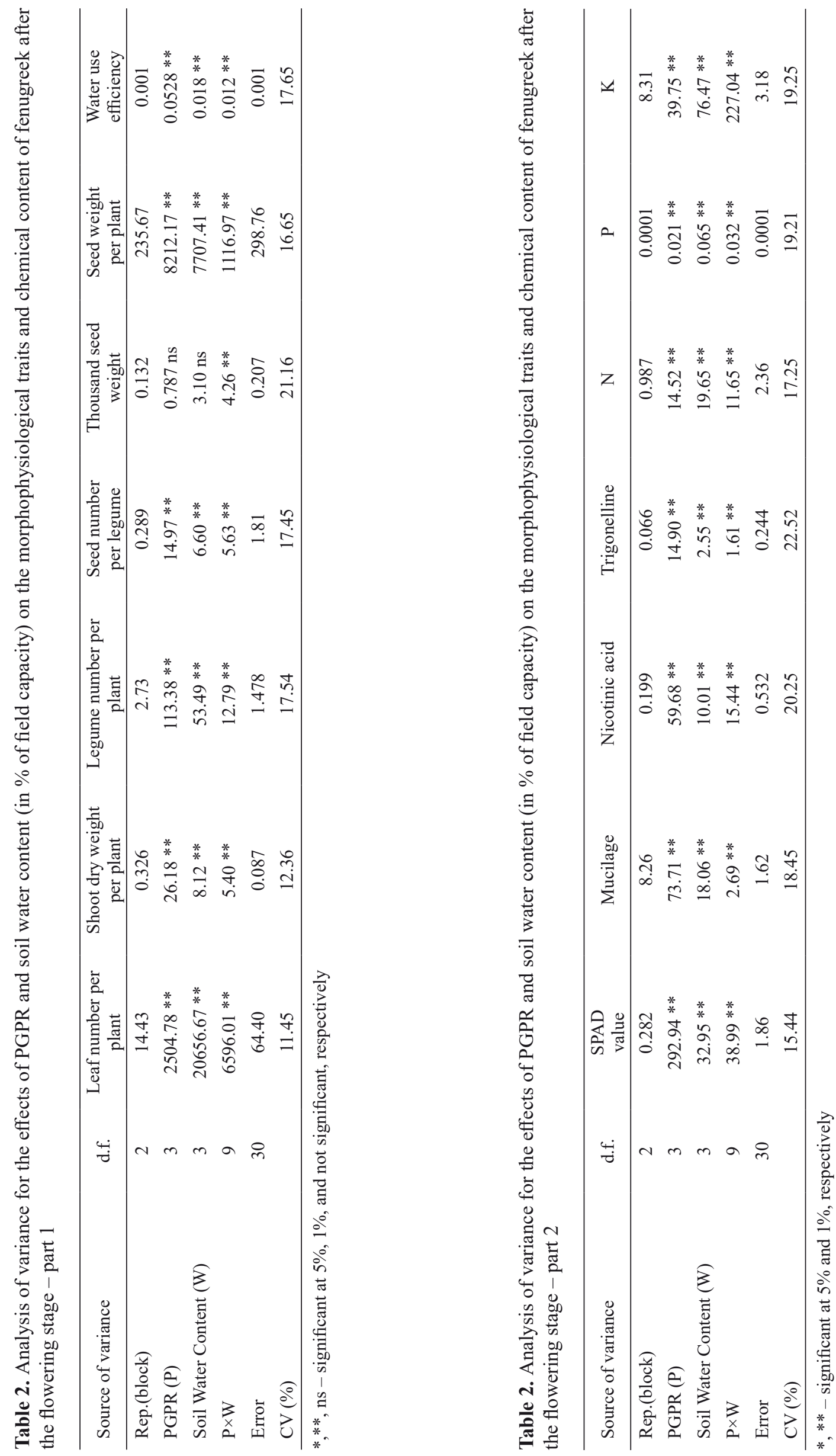


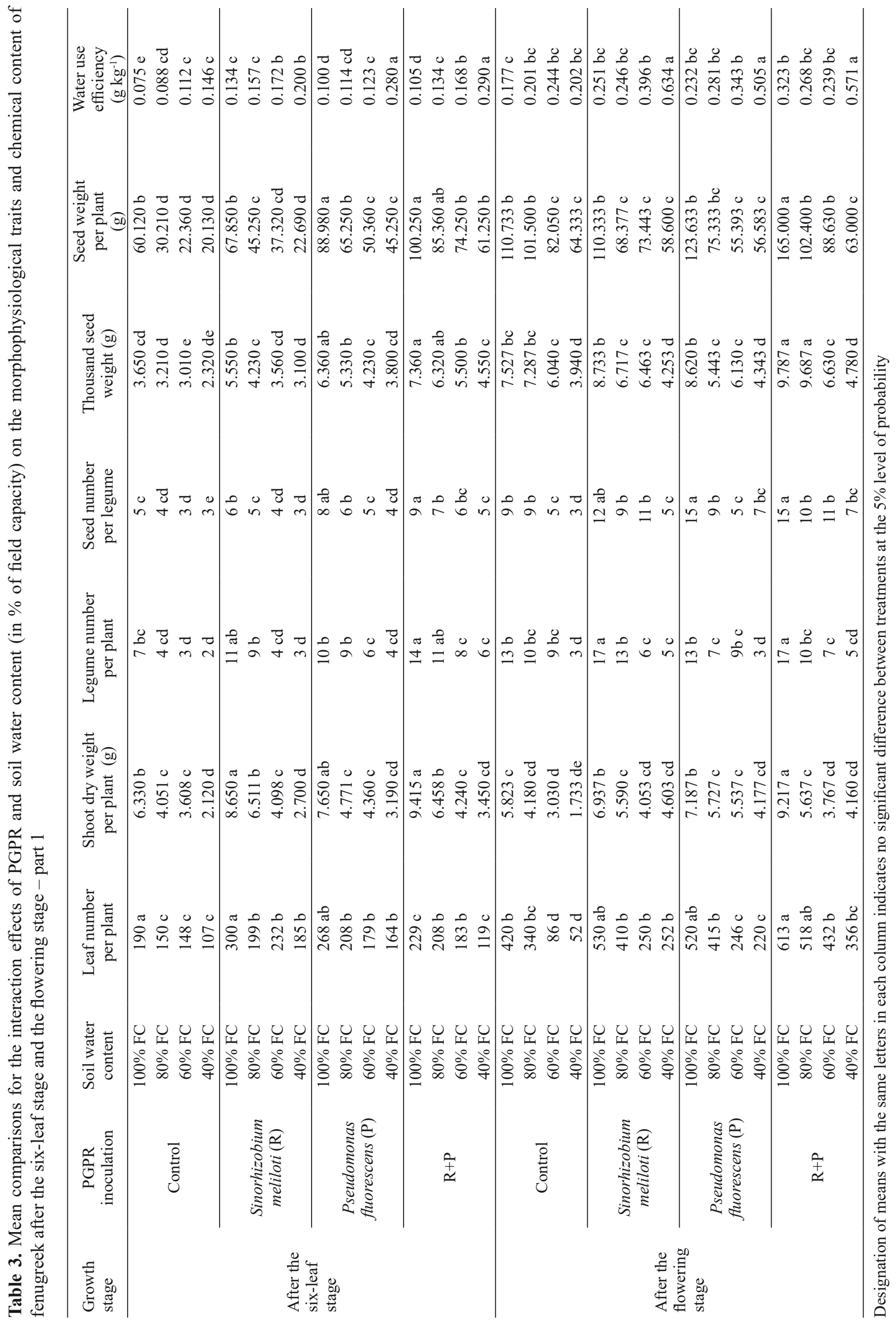




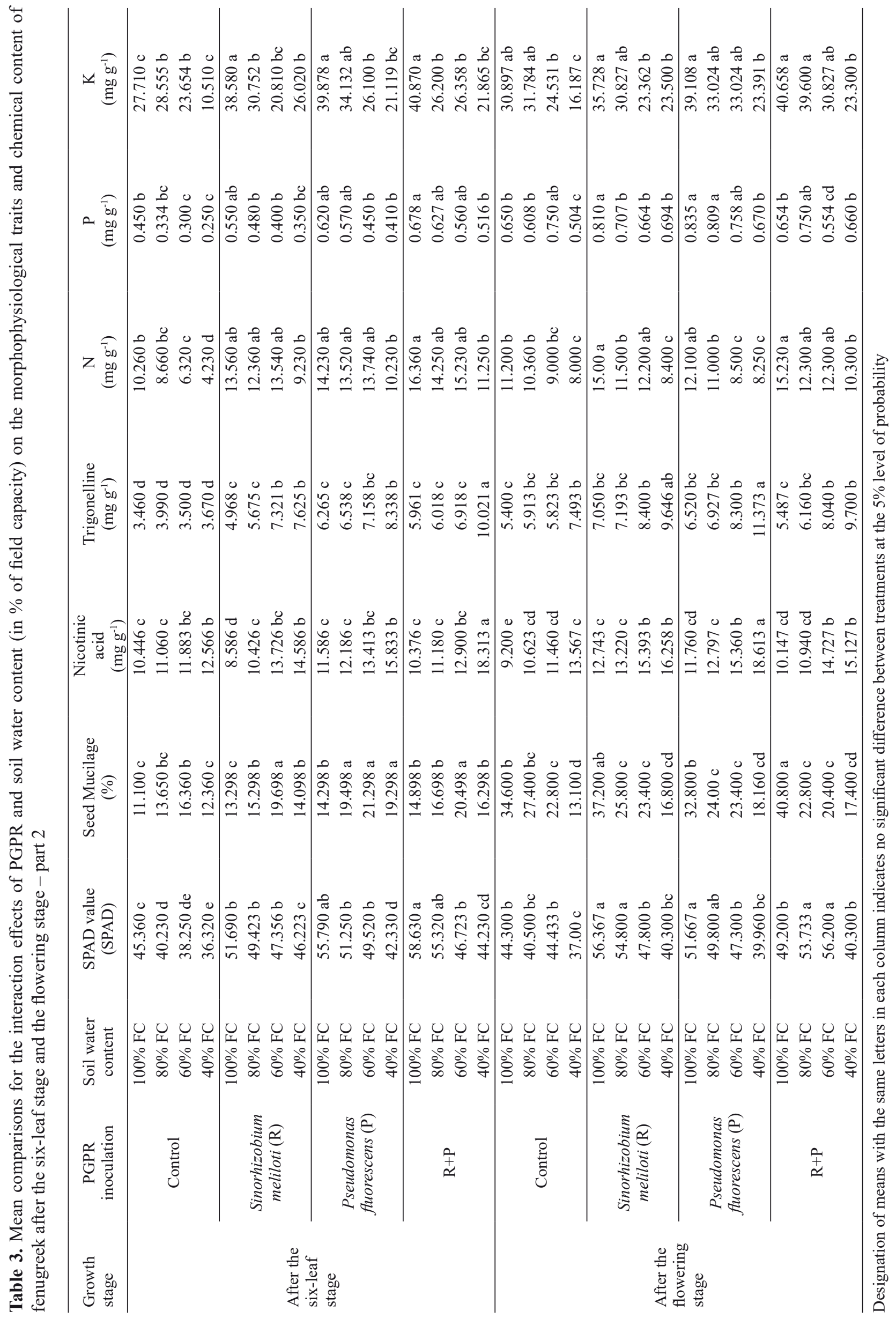




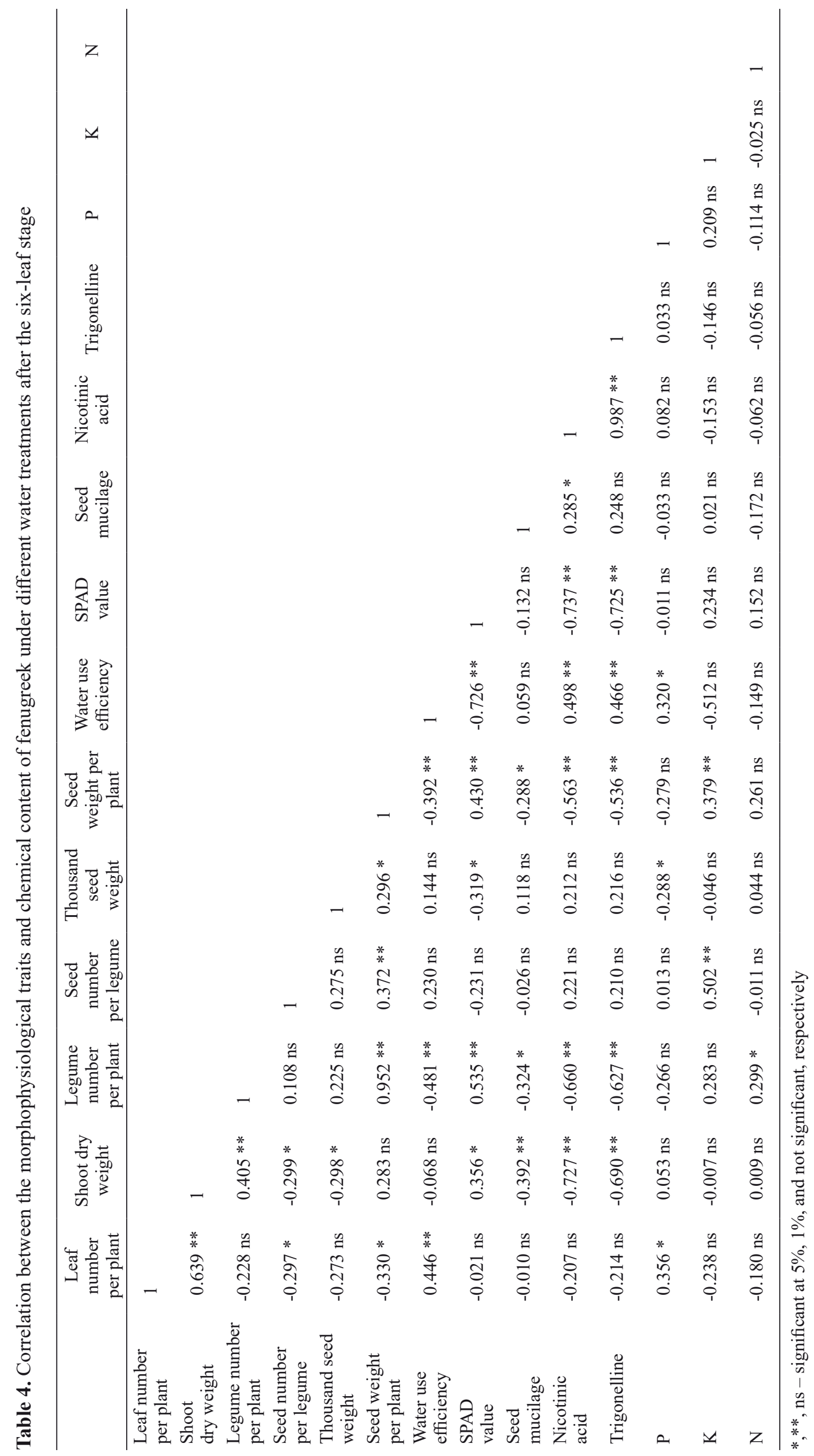




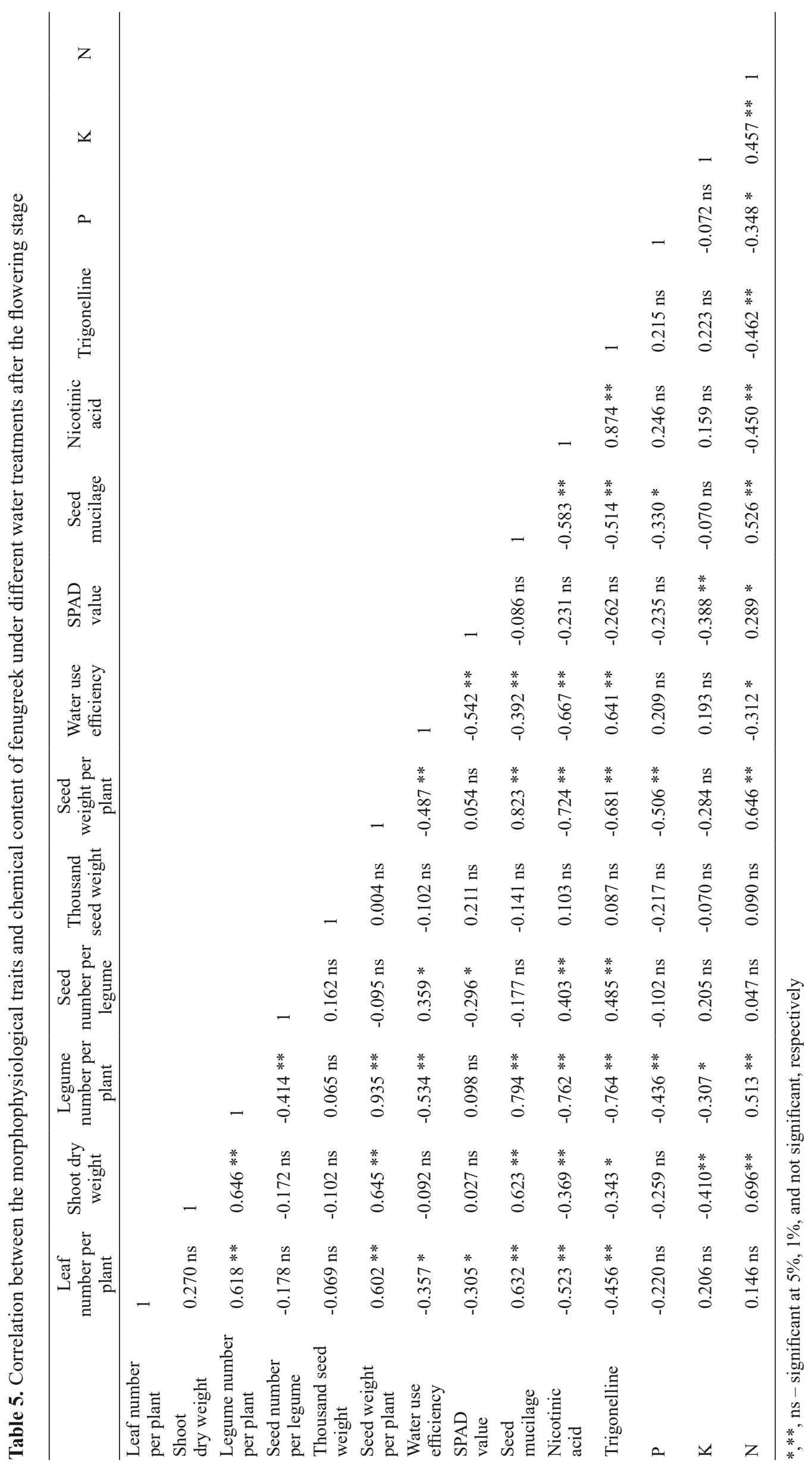


water use efficiency. However, the trigonelline content had a positive and significant correlation with nicotinic acid content. Interestingly, seed weight per plant had significant and negative correlations with water use efficiency and secondary metabolites including trigonelline, nicotinic acid content and seed mucilage, but it had positive and significant correlations with 1000 seed weight, seed number per legume, and legume number per plant (Tab. 4).

Considering the correlations between the traits in the $2^{\text {nd }}$ experiment (Tab. 5), trigonelline showed a significant $(p \leq 0.01)$ and positive correlation with nicotinic acid. Although trigonelline and nicotinic acid showed significant $(p \leq 0.01)$ and negative correlations with leaf number per plant, shoot dry weight, legume number per plant, seed weight per plant and mucilage content, they had a significant and positive correlation with seed number per legume. However, trigonelline had positive and significant correlations with nicotinic acid content and water use efficiency. Also, the seed weight per plant had significant and positive correlations with leaf number per plant, shoot dry weight and legume number per plant (Tab. 5).

\section{DISCUSSION}

According to the obtained results, the effect of inoculation with plant growth promoting rhizobacteria on the morphophysiological and phytochemical traits of fenugreek was significant following the induction of water stress after the sixleaf stage ( $1^{\text {st }}$ experiment) and the flowering stage ( $2^{\text {nd }}$ experiment). In the first experiment, the highest number of leaves was obtained by inoculation with S. meliloti at $100 \% \mathrm{FC}$, while in the $2^{\text {nd }}$ experiment, inoculation with $S$. meliloti + P. fluorescens at $100 \%$ $\mathrm{FC}$ was the best treatment in respect of the number of leaves. The same results were obtained for shoot dry weight per plant in both experiments. It has been reported that PGPR can delay flowering time and increase biomass weight, and can also improve the resistance of plants to stress conditions (Lee et al., 2013). These results are in line with those of Jaleel et al. (2007) on Catharanthus roseus. Undesirable stress causes a breakdown of chloroplasts, decomposition of chlorophyll, enhances the activity of the chlorophyllase enzyme and results in a reduction of photosynthesis, reduced leaf development and reduced plant production (Taiz and Zeiger, 2000). Plant growth promoting bacteria involved in nitrogen fixation and also phosphorus and potassium solubilization increase their uptake, which leads to an increase in the efficiency of photosynthesis, leaf expansion and plant biomass growth (Souza et al., 2015). The highest number of legumes per plant, seeds per legume, 1000 seed weight, and seed weight per plant was obtained by inoculation with $S$. meliloti + P. fluorescens at $100 \% \mathrm{FC}$ in both experiments. These results are in agreement with the results of Mishra et al. (2010), and they indicated that PGPR could ameliorate the negative effects of stress conditions by improving seed germination and weight, drought tolerance and growth. Lack of water in the soil disrupts the absorption of the elements and seed production (Mandal et al., 1986). Malik et al. (1992), in their studies on legume plants reported that growth stimulating bacteria increased plant access to nitrogen, phosphorus and potassium, and increased the number of pods, seeds and 1000 grain weight. The maximum water use efficiency was obtained by the $S$. meliloti $+P$. fluorescens inoculation at $40 \% \mathrm{FC}$ in the first experiment, while the greatest water use efficiency was obtained with S. meliloti at $40 \% \mathrm{FC}$ after the flowering stage. It had previously been reported that PGPR application could reduce the adverse effects of environmental stress on plant growth and thus improve their survival and performance (Dimkpa et al., 2009). Also, nitrogen improves water use efficiency because it prevents membrane damage in drought stress and improves osmotic regulation (Saneoka et al., 2004). The maximum SPAD value was obtained by the $S$. meliloti $+P$. fluorescens inoculation at $100 \% \mathrm{FC}$ in the $1^{\text {st }}$ experiment. Inoculation with S. meliloti at $100 \%$ FC resulted in the greatest SPAD value in the fenugreek plants in the $2^{\text {nd }}$ experiment. These results are similar to the results of Ahemad and Khan (2012) on Vigna radiata L. plants. Anjum et al. (2003), in an experiment with the barley plant had proved that drought stress led to the destruction of chloroplasts and a reduction in chlorophyll content. On the other hand, inoculation with Pseudomonas and Sinorhizobium bacteria increased the vitality and the concentrations of phosphorus and potassium in wheat components (Egamberdiyeva and Hoflich, 2003). Inoculation of clover plants with Sinorhizobium meliloti bacteria under drought stress caused nitrogen fixation and an increase in chlorophyll content (Dursun et al., 2010). Previous studies suggest that increased photosynthetic activity was a consequence of a higher $\mathrm{N}$ incorporation which contributed to the formation of the SPAD value (Baset et al., 2010).

Micro-organisms (including bacteria) and growth hormones are known as biological and chemical stimuli in the synthesis of secondary 
metabolites in medicinal plants (Ping and Boland, 2004). In the first experiment, the highest amount of seed mucilage was obtained by the application of P. fluorescens at $60 \% \mathrm{FC}$, while in the $2^{\text {nd }}$ experiment the highest result was obtained by inoculation with S. meliloti + P. fluorescens at $100 \%$ FC. The greatest amounts of nicotinic acid and trigonelline were achieved by inoculation with $S$. meliloti and P. fluorescens at $40 \% \mathrm{FC}$ in the first experiment, and by the $P$. fluorescens inoculation at $40 \% \mathrm{FC}$ in the $2^{\text {nd }}$ experiment. These results agreed with the findings of Ghorbanli and Niakan (2005) for soybean, Cho et al. (2011) for peanut, and Sanchez-Blanco et al. (2004) for rosemary. Trigonelline synthesis was activated when plants encountered insufficient water and also rhizobacterial inoculation. This result showed that trigonelline was synthesized under the deficiency of nitrogen due to inactive symbiotic reaction. According to Tramontano et al. (1986), accumulation of trigonelline apparently occurred in legumes because of a lack of essential nutrients such as nitrogen and phosphorus (Tramontano et al., 1986; Cho et al., 2011). Among the PGPR, the Pseudomonas sp. is notable due to their ability to solubilize soil unavailable $\mathrm{P}$ as well as to produce a wide variety of metabolites like auxins, ACC deaminase enzymes, and siderophores. In addition to increasing nutrient availability, PGPR have the potential to produce a wide range of phytohormones to enhance plant growth, which can also contribute to a better growth of fenugreek plants when inoculated with these bacteria. This result is important, since the application of an integrated fertilizer not only enhanced fenugreek growth and forage weight but also reduced the need for chemical $\mathrm{N}-\mathrm{P}-\mathrm{K}$ fertilizers, which offers greater economic and environmental benefits (Dadrasan et al., 2015). Due to the induction of drought stress, nitrogen is used to produce secondary metabolites, and most of the metabolites are used to prevent cellular oxidation (Turtola et al., 2003). Cho et al. (2011) had reported that the trigonelline concentration in peanut increased under drought stress. Rahimi et al. (2014) announced that the amount of seed mucilage of plants increased under water scarcity conditions, which helped to reduce the loss of water. However, the synthesis of secondary metabolites is induced by microorganisms (Bouchereau et al., 1996). For example, bacteria produce phytohormones, which play the role of stimulants in the production of secondary metabolites (Ping and Boland, 2004). Studies on medicinal plants have shown that the specific pathways of secondary metabolite synthesis are induced by the application of microorganisms (Sanchez-Blanco et al., 2004).

\section{CONCLUSIONS}

The results showed that inoculation with plant growth promoting rhizobacteria (PGPR) significantly improved the morphophysiological and phytochemical traits of fenugreek (Trigonella foenum-graecum L.) under different water availability levels, especially under the conditions of soil water restriction. Generally, the best results were obtained by integrated inoculation with Sinorhizobium meliloti and Pseudomonas fluorescens at $40 \%$ FC after the flowering stage for increasing the trigonelline and nicotinic acid content and water use efficiency, and also, at $100 \%$ FC after the flowering stage for increasing seed mucilage and seed weight. Thus, PGPR application can reduce the adverse effect of soil water restriction on plant growth and improve their performance and biosynthesis of secondary metabolites under the conditions of soil water restriction.

\section{ACKNOWLEDGEMENT}

We thank the research group of the Cultivation and Development Department of Medicinal Plants for making their laboratory facilities and equipment available to us.

\section{FUNDING}

The research was supported by the Institute of Medicinal Plants, ACECR.

\section{AUTHOR CONTRIBUTIONS}

All the authors contributed to this work, including the development of ideas, writing and revisions of the content.

\section{CONFLICT OF INTEREST}

Authors declare no conflict of interest.

\section{REFERENCES}

Aeron A., Kumar S., Pandey P., Maheshwari D.K., 2011. Emerging role of plant growth promoting rhizobacteria in agrobiology. In: Bacteria in Agrobiology: Crop Ecosystems. D.K. Maheshwari (Ed.), Springer-Verlag, Berlin, Heidelberg, 1-36.

Ahemad M., Khan M.S., 2012. Alleviation of fungicideinduce phytotoxicity in greengram [Vigna radiata $(\mathrm{L}$. Wilczek] using fungicide-tolerant and plant growth 
promoting Pseudomonas strain. Saudi J. Biol. Sci. 19, 451-459.

Ajabnoor M.A., Tilmisany A.K., 1988. Effect of Trigonella foenum-graceum on blood glucose levels in normal and alloxan-diabetic mice. J. Ethnopharmacol. 22, 45-49.

Aliabadi-Farahani H., Valadabadi S.A., Daneshian J., Khalvati M.A., 2009. Evaluation changing of essential oil of balm (Melissa officinalis L.) under water deficit stress conditions. J. Med. Plants Res. 3, 329-333.

Anjum F., Yaseen M., Rasool E., Wahid A., Anjum S., 2003. Water stress in barley (Hordeum vulgare L.) II. Effect on chemical composition and chlorophyll contents. Pak. J. Agr. Sci. 40(1-2), 45-49.

BAKer W.H., ThOMPSON T.L., 1992. Determination of total nitrogen in plant samples by Kjeldahl. In: Plant analysis reference procedures for the Southern Region of the United States. C.O Plank (Ed.), Southern Cooperative Series Bulletin: Washington, DC, USA, 13-16.

Bartels D., Sunkar R., 2005. Drought and salt tolerance in plants. Crit. Rev. Plant Sci. 24, 23-58.

Baset Mia M.A., Shamsuddin Z.H., Wahab Z., MARZIAH M., 2010. Effect of plant growth promoting rhizobacterial (PGPR) inoculation on growth and nitrogen incorporation of tissue-cultured $\mathrm{Musa}$ plantlets under nitrogen-free hydroponics condition. Aust. J. Crop Sci. 4(2), 85-90.

Basch E., Ulbricht C., Kuo G., Szapary P., Smith M., 2003. Therapeutic applications of fenugreek. Altern. Med. Rev. 8, 20-27.

Bharti N., Barnawal D., Awasthi A., Yadav A., Kalra A., 2014. Plant growth promoting rhizobacteria alleviate salinity induced negative effects on growth, oil content and physiological status in Mentha arvensis. Acta Physiol. Plant. 36, 45-60.

Bouchereau A., Clossais-Besnard N., Bensaoud A., LePORT L., RENARD M., 1996. Water stress effects on rapeseed quality. Eur. J. Agron. 5, 19-30.

BraY E.A., 1997. Plant responses to water deficit. Trends Plant Sci. 2, 48-54.

BraY E.A., 2004. Genes commonly regulated by waterdeficit stress in Arabidopsis thaliana. J. Exp. Bot. 55, 2331-2341.

Cho Y., Kodjoe E., Puppala N., Wood A.J., 2011. Reduced trigonelline accumulation due to rhizobial activity improves grain yield in peanut (Arachis hypogaea L.). Acta Agr. Scand, B-S.P. 61(5), 395-403.

Dadrasan M., Chaichi M.R., Pourbabaee A.A., YazDani D., Keshavarz-Afshar R., 2015. Deficit irrigation and biological fertilizer influence on yield and trigonelline production of fenugreek. Ind. Crop. Prod. 77, 156-162.

Danesh Talab S., Mehrafarin A., Naghdi Badi H., Khalighi-Sigaroodi F., 2014. Changes in growth and trigonelline/mucilage production of fenugreek
(Trigonella foenum-graecum L.) under plant growth regulators application. J. Med. Plants. 3(51), 15-25.

Dimkpa C., Weinand T., Asch F., 2009. Plantrhizobacteria interactions alleviate abiotic stress conditions. Plant Cell Environ. 32, 1682-1694.

DodD I.C., Ryan A.C., 2016. Whole plant physiological responses to water deficit stress. Wiley \& Sons Ltd, Chichester, UK, 1-9.

Dursun A., Ekinci M., Donmaz F.M., 2010. Effects of foliar application of plant growth promoting bacterium on chemical contents, yield and growth of tomato (Lycopersicon esculentum L.) and cucumber (Cucumis sativus L.). Pak. J. Bot. 42(5), 3349-3356.

Egamberdiyeva D., Hoflich G., 2003. Influence of growth-promoting bacteria on the growth of wheat in different soils and temperatures. Soil Biol. Biochem. 35, 973-978.

El-Tarabily K.A., Sivasithamparam K., 2006. Nonstreptomycete actinomycetes as biocontrol agents of soil-borne fungal plant pathogens and as plant growth promoters. Soil Biol. Biochem. 38, 1505-1520.

Fernandez-Aparicio M., Emeran A.A., Rubiales D., 2008. Control of Orobanche crenata in legumes intercropped with fenugreek (Trigonella foenumgraecum L.). Crop Prot. 27, 653-659.

Ghorbanli M., NiaKan M., 2005.The effect of drought stress on soluble sugar, total protein, proline, phenolic compound, chlorophyll content and nitrate reductase activity in soybean (Glycine max L. cv. Gorgan3). J. Sci. (Kharazmi University) 5(1-2), 537-550.

Govindasamy V., Senthilkumar M., Gaikwad K., ANNAPURNA K., 2008. Isolation and characterization of ACC deaminase gene from two plant growthpromoting rhizobacteria. Curr. Microbiol. 57, 312-317.

Havlin J.L., SoltanPOUR P.N., 1980. A nitric acid plant tissue digest method for use with inductively coupled plasma spectrometry. Commun. Soil Sci. Plant Anal. 11, 969-980.

Hummel I., Pantin F., Sulpice R., Piques M., Rolland G., Dauzat M., ET Al., 2010. Arabidopsis plants acclimate to water deficit at low cost through changes of carbon usage: an integrated perspective using growth, metabolite, enzyme, and gene expression analysis. Plant Physiol. 154, 357-372.

Jaleel C.A., Manivannan P., Sankar B., Kishorekumar A., Gopi R., Somasumdaram R. et AL., 2007. Pseudomonas fluorescens enhances biomass yield and ajmalicine production in Catharanthus roseus under water deficit stress. Colloid Surface B 60, 7-11.

JING Y.D., He Z.L., YANG X.E., 2007. Role of soil rhizobacteria in phytoremediation of heavy metal contaminated soils. J. Zhejiang Univ. Sci. B 8, $192-$ 207.

Karimi H.R., Maleki Kuhbanani A., Roosta H.R., 2014. Evatuation of inter-specific hybrid of $P$. atlantica $\mathrm{L}$. and $P$. vera cv. Badami Riz-E- Zarand as pistachio rootstock to salinity stress according to some growth 
indices and eco-physiological and bichemichcal parameters. J. Stress Physiol. Biochem. 10(3), 5-17.

Khosravi M.T., Mehrafarin A., Naghdi Badi H.A., Hajiaghaee R., Khosravi E., 2011. Effects of methanol and ethanol application on yield of Echinacea purpurea L. in Karaj region. J. Herb. Drugs 2, 121-128.

Koshiro Y., Zheng X.Q., Wang M.L., Nagai C., Ashinara H., 2006. Changes in content and biosynthetic activity of caffeine and trigonelline during growth and ripening of Coffea arabica and Coffea canephora fruits. Plant Sci. 171, 242-250.

LeE K.J., OH B.T., Seralathan K.K., 2013. Advances in plant growth promoting rhizobacteria for biological control of plant diseases. In: Bacteria in Agrobiology: Disease Management. D.K. Maheshwari (Ed.), Springer-Verlag, Berlin, Heidelberg, 1-13.

Malik M.A., Akram M., Tanvir A., 1992. Effect of planting geometry and fertilizer on growth, yield and quality of a new sunflower cultivar SF-100. J. Agric. Res. 30, 59-63.

MANDAl B.K., Ray P.K., Dasgupta S., 1986. Water use by wheat, chickpea and mustard grown as sole crops and intercrops. Indian J. Agr. Sci. 56, 187-193.

Martin M.J., Pablos F., Bello M.A., Gonzales A.G., 1997. Determination of trigonelline in green and roasted coffee from single column ionic chromatography. Fresenius J. Anal. Chem. 357, 357358.

Miraldi E., Ferri S., Mostaghimi V., 2001. Botanical drugs and preparations in the traditional medicine of West Azerbaijan (Iran). J. Ethnopharmacol. 75, 77-87.

Mishra M., Kumar U., Mishra P.K., Prakash V., 2010. Efficiency of plant growth promoting rhizobacteria for the enhancement of Cicer arietinum L. growth and germination under salinity. Adv. Biol. Res. 4: 92-96.

PING L., Boland W., 2004. Signals from the underground: bacterial volatiles promote growth in Arabidopsis. Trends Plant Sci. 9(6), 263-266.

Rahimi A., Jahansoz M.R., Rahimian MashHadi H., 2014. Effect of drought stress and plant density on quantity and quality charactristics of Isabgol (Plantago ovata) and French psyllum. J. Crop Prod. Process. 12(4), 143-156.

Ryu C.M., Farag M.A., Hu C.H., Reddy M.S., Wei H.X., PARE P.W., ET AL., 2003. Bacterial volatiles promote growth in Arabidopsis. Proc .Natl. Acad. Sci. USA 100, 4927-4932.

Sabale V., Patel V., Paranjape A., Sabale P., 2009. Isolation of fenugreek seed mucilage and its comparative evaluation as a binding agent with standard binder. Int. J. Pharm. Res. 1, 56-62.

Salekdeh G.H., Reynolds M., Bennett J., Boyer J., 2009. Conceptual framework for drought phenotyping during molecular breeding. Trends Plant Sci. 14, 488496.

Sanchez-Blanco M.J., Ferradez T., Morales M.A., Morte A., Alarcon J.J., 2004. Variations in water status, gas exchange, and growth in Rosmarinus officinalis plants infected with Glomus deserticola under drought conditions. J. Plant Physiol. 161, 675682.

Sandhya V., Ali S.Z., Grover M., Reddy G., Venkateswarlu B., 2010. Effect of plant growth promoting Pseudomonas spp. on compatible solutes, antioxidant status and plant growth of maize under drought stress. Plant Growth Regul. 62, 21-30.

Saneoka H., Moghaieb R.E.A., Premachandra G.S., FuJITA K., 2004. Nitrogen nutrition and water stress effects on cell membrane stability and leaf water relations in Agrostis palustris Huds. Environ. Exp. Bot. 52, 131-138.

Sharma R.D., RaghuRAm T.C., 1990. Hypoglycaemic effect of fenugreek seeds in non-insulin dependent diabetic subjects. Nutr. Res. 10, 731-739.

Shaukat K., Affrasayab S., Hasnain S., 2006. Growth responses of Triticum aestivum to plant growth promoting rhizobacteria used as a biofertilizer. Res. J. Microbiol. 1, 330-338.

Souza R., Ambrosini A., Passaglia L.M.P., 2015. Plant growth-promoting bacteria as inoculants in agricultural soils. Genet. Mol. Biol. 38(4), 401-419.

Srivastava S., Yadav A., Seem K., Mishra S., Chaudhary V., NAutiYal C.S., 2008. Effect of high temperature on Pseudomonas putida NBRI0987 biofilm formation and expression of stress sigma factor RpoS. Curr. Microbiol. 56, 453-457.

Taiz L., Zeiger E., 2000. Plant Physiology. Sinauer Associates, Inc. Publisher, Sunderland, Massachusetts, USA.

Tramontano W.A., Mcginley P.A., Ciancaglini E.F., Evans, L.S., 1986. A survey of trigonelline concentrations in dry seeds of the dicotyledoneae. Environ. Exp. Bot. 26, 197-205.

Turtola S., Manninen A.M., Rikala R., Kainulainen P., 2003. Drought stress alters the concentration of wood terpenoids in scots pine and Norway spruce seedling. J. Chem. Ecol. 29, 1981-1995.

VAN LoON L.C., 2007. Plant responses to plant growthpromoting rhizobacteria. Eur. J. Plant Pathol. 119, 243-254.

VESSEY J.K., 2003. Plant growth promoting rhizobacteria as biofertilizers. Plant Soil 255, 571-586.

Warke V.B., Deshmukh T.A., Patil V.R., 2011. Development and validation of RP-HPLC method for estimation of diosgenin in pharmaceutical dosage form. Asian J. Pharm. Clin. Res. 4, 126-128.

YANG J., Kloepper J.W., Ryu C.M., 2009. Rhizosphere bacteria help plants tolerate abiotic stress. Trends Plant Sci. 14, 1-4.

Zheng X.Q., Ashinara H., 2004. Distribution, biosynthesis and function of purine and pyridine alkaloids in Coffea arabica seedlings. Plant Sci. 166, 807-813.

Received October 30, 2017; accepted February 12, 2018 